\title{
PHÁT HIỆN THUỐC NHUQ̣̂M MÀU BẦNG KỸ THUẬT SERS, SỬ DỤNG CÁC ĐẾ SERS LÀM TỪ CÁC HẠT NANO BẠC LẮNG ĐỌNG \\ TRÊN LỚP SILIC CACBUA VÔ ĐỊNH HÌNH XỐP
}

\section{Detection of dye by SERS technique, using SERS substrates made of silver nanoparticles deposited on porous amorphous silicon carbide layer}

\author{
ThS. Cao Tuấn Anh", ThS. Nguyễn Thúy Nga ${ }^{* *}$ \\ ThS. Lương Trúc Quỳnh Ngân ${ }^{* * *}$, GS. TS. Đào Trần Cao ${ }^{* * *}$
}

\section{TÓM TẮT}

Trong báo cáo này chúng tôi trình bày các kết quả bước đầu về việc sủ dung các hạt nano bac (AgNPs) lắng đọng trên lớp silic cacbua xốp (PSiC) cho việc phát hiện dấu vết của malachite green (MG) sủ dụng hiệu úng tán xạ Raman tăng cuờng bề mặt (SERS). Cu thể hơn, các đế SERS đurợc chế tạo tù AgNPs lắng đọng trên bề mặt của lớp silic cacbua vô định hình xốp (AgNPs@PSiC). Các kết quả cho thấy sụ thay đổi trong cấu trúc của lớp PSiC và/hoặc AgNPs ảnh huởng tới chi số tăng cuờng Raman của các đế SERS. Với đế AgNPs@PSiC tốt nhất, hàm luợng $M G$ thấp tới $10^{-9} M$ có thể phát hiện được.

Tù khóa: đế SERS, silic cacbua xốp, ăn mòn anốt, malachite green, hạt nano bạc.

\begin{abstract}
In this report we present the initial results of the use of silver nanoparticles (AgNPs) deposited on porous silicon carbide (PSiC) layer for trace detection of malachite green using the surface-enhanced Raman scattering (SERS) effect. More specifically, the SERS substrates were fabricated from AgNPs deposited onto the surface of a porous amorphous silicon carbide layer (AgNPs@PSiC).Results showed that the change of the structure of PSiC layer and/or AgNPs affect to the Raman enhancement factor of the SERS substrates. With the best AgNPs@PSiC substrate, the MG concentration as low as $10^{-9} \mathrm{M}$ can be detected.

Keywords: SERS substrate, porous silicon carbide, anodic etching, malachite green, silver anoparticles.

\section{Giới thiệu}

Tán xạ Raman tăng cường bề mặt (Surface Enhanced Raman Spectroscopy - SERS). Đây là một phương pháp được phát triển để phát hiện một lượng rất nhỏ của các phân tử hữu cơ bằng cách ghi phổ tín hiệu tán xạ Raman đặc trưng của chúng và phương pháp này đang được nghiên cứu và sử dụng rộng rãi trong nhiều lĩnh vực khác nhau như sinh học, hóa học, y học... [1-4]. Với việc phát hiện được lượng vết của các phân tử hữu cơ, SERS có thể giúp chúng ta phát hiện được dư lượng thuốc bảo vệ thực vật, chất mầu trong thực phẩm [5-6, 20]. Với việc phát hiện được vết của các

\footnotetext{
* Trường Đại học Tân Trào

*** Viện Vật lý, 10 Đào Tấn, Hà Nội, Việt Nam

**** Viện Khoa học Vật liệu, 18 Hoàng Quốc Việt, Hà Nội, Việt Nam
} 
virus, SERS có thể giúp chúng ta chẩn đoán bệnh tật [7-8]. Do đó, hiện nay SERS là đề tài đang được các nhà khoa học trên thế giới nghiên cứu rất nhiều.

Tán xạ Raman là một công cụ rất hữu ích để xác định cấu trúc phân tử. Điều này xuất phát từ nguồn gốc xuất hiện của loại tán xạ này. Trong hiệu ứng tán xạ Raman, ánh sáng tới được tán xạ không đàn hồi bởi vật liệu và tần số của nó bị dịch đi một khoảng bằng năng lượng dao động của phân tử của vật liệu đó. Vì vậy, phổ tán xạ Raman cung cấp thông tin về các dao động phân tử và do mỗi loại phân tử đều có một số loại dao động đặc trưng nên nó cho ta biết thành phần phân tử của chất được phân tích. Tuy vậy, tán xạ Raman lại bị hạn chế rất nhiều do xác suất xảy ra rất thấp của nó. Người ta đã tính ra rằng, trung bình chỉ có một photon bị tán xạ Raman trong số $10^{6}-10^{8}$ photon rơi vào vật liệu [9]. Chính vì vậy mà cường độ của tín hiệu Raman đo được thường rất yếu. Một bước ngoặt lớn đã xảy ra vào năm 1974, khi nhóm nghiên cứu của Fleischmann đã phát hiện ra rằng sự có mặt của một điện cực bạc nhám sẽ làm cho cường độ tín hiệu Raman của pyridin hấp thụ trên bề mặt điện cực đó tăng lên nhiều lần [10]. Người ta gọi hiệu ứng này là tán xạ Raman tăng cường bề mặt-SERS. Từ đây bắt đầu kỷ nguyên của SERS như một kỹ thuật phân tích xác định sự có mặt của những lượng vết của các phân tử hữu cơ và sinh học. Đặc biệt là từ khi công nghệ nano có được những bước phát triển mạnh mẽ thì SERS mới được quan tâm nghiên cứu nhiều hơn.

Cho đến nay người ta vẫn chưa rõ về các lý do cụ thể gây ra SERS. Tuy thế, nói chung giới nghiên cứu đều đồng ý rằng nguyên nhân chủ yếu gây ra SERS là hiện tượng Cộng hưởng Plasmon Bề mặt (Surface Plasmon Resonance - SPR), trong đó plasmon là khái niệm dùng để chỉ dao động tập thể của các điện tử tự do của kim loại. Giới hạn phát hiện của kỹ thuật SERS phụ thuộc rất nhiều vào cấu trúc của các đế SERS. Một trong những vấn đề được quan tâm chủ yếu về SERS trong thời gian gần đây là chế tạo các đế SERS với độ nhạy cao, dễ chế tạo, giá thành rẻ và có độ lặp lại tốt. Rất nhiều các nghiên cứu đã được thực hiện để chế tạo ra các đế SERS sử dụng các hạt nanô kim loại quý, trong đó loại đế phổ biến nhất là dung dịch dạng huyền phù của các hạt nanô kim loại [11-12]. Các đế SERS loại này được báo cáo là cung cấp sự tăng cường SERS khá tốt nhưng lại có nhược điểm lớn là kém ổn định và độ lặp lại không tốt do các hạt nanô kim loại liên tục chuyển động và thường bị tụ lại với nhau. Một cách tiếp cận để khắc phục được các hạn chế trên là gắn cố định các hạt nanô kim loại trên một đế rắn có bề mặt gồ nghề [13-14], hoặc các hệ dây nano sắp xếp thẳng hàng [1, 15]. Trong cách tiếp cận này thì các hạt nano kim loại được sử dụng nhiều nhất là các hạt nano bạc (AgNPs) nhờ có độ ổn định cao, có cộng hưởng plasmon rộng trong các vùng nhìn thấy và hồng ngoại gần và đặc biệt là các AgNPs cho hiệu suất tăng cường SERS rất tốt [16].

Trong bài viết này chúng tôi trình bày về việc chế tạo hệ các AgNPs trên bề mặt lớp silic cacbua vô định hình xốp để sử dụng làm đế SERS (đế này có thể được viết tắt là AgNPs@PSiC). Các AgNPs đã được lắng đọng trên bề mặt Si bằng phương pháp lắng đọng hóa học. Chúng tôi đã thay đổi các thông số chế tạo để thu được hệ các AgNPs với hình thái, kích thước và mật độ tối ưu đối với phép đo SERS. Các kết quả thu được đã chỉ ra rằng, các AgNPs đã được lắng đọng lên trên đế PSiC với kích thước và mật độ khác nhau và có thể điều khiển được. Khi khảo sát hiệu ứng SERS trên các đế AgNPs@PSiC chúng tôi đã quan sát thấy 
rằng hình thái học của các $\mathrm{AgNPs}$ trên bề mặt $\mathrm{PwPC}$ cũng như hình thái học của lớp $\mathrm{PSiC}$ có ảnh hưởng tới sự tăng cường SERS của đế. Ngoài ra chúng tôi còn thấy rằng trong điều kiện tối ưu, khi sử dụng các phân tử malachite green $(\mathrm{MG})$ làm chất thử, đế AgNPs@PSiC có thể phát hiện nồng độ $\mathrm{MG}$ nhỏ đến $10^{-9} \mathrm{M}$.

\section{Thí nghiệm}

Đầu tiên, các đế PSiC được chế tạo bằng ăn mòn anốt trong dung dịch $0,5 \% \mathrm{HF} / \mathrm{H}_{2} \mathrm{O}$ trong thời gian 50 phút với các mật độ dòng từ 0,5 đến $3,5 \mathrm{~mA} / \mathrm{cm}^{2}$ như đã trình bày trong một nghiên cứu khác của chúng tôi [17]. Sau khi chế tạo, đế PSiC được rửa bằng nước khử vài lần sau đó được ngâm trong dung dịch $10 \%$ HF trong 10 phút để loại bỏ hết lớp ôxít, sau khi ngâm trong dung dịch $\mathrm{HF}$ các mẫu được rửa lại vài lần bằng nước khử. Sau khi rửa các mẫu được ngâm trong dung dịch nước của $\mathrm{HF} / \mathrm{AgNO}_{3}=4,6(\mathrm{M}) / 25(\mathrm{mM})$ để lắng đọng các hạt $\mathrm{Ag}$ với thời gian từ 1-7 phút để tạo ra các đế $\mathrm{AgNPs} @ \mathrm{PSiC}$. Các đế này sau đó được đem ra rửa lại bằng nước khử rồi để khô tự nhiên. Các đế AgNPs@PSiC được nhỏ MG với các nồng độ khác nhau lên để kiểm tra hiệu ứng SERS.

Hình thái bề mặt và cấu của các đế $\mathrm{AgNPs} @ S i$ được khảo sát bằng hệ Hiện vi điện tử quét trường (FE-SEM) S-4800 (Hitachi, Nhật Bản) và hệ đo phổ tia X phân giải theo năng lượng (Energy-dispersive X-ray spectroscopy - EDX) đi kèm với hệ đo SEM. Các phép đo SERS đã được tiến hành bằng cách nhỏ $50 \mu$ dung dịch $\mathrm{MG}$ trong nước với nồng độ khác nhau lên trên bề mặt đế AgNPs @PSiC. Diện tích của các đế là $1 \times 1 \mathrm{~cm}^{2}$. Sau đó các mẫu được để khô tự nhiên trong không khí tại nhiệt độ phòng. Phổ Raman của các mẫu được ghi với laser kích thích có bước sóng 532 nm.

\section{Kết quả và thảo luận}

Đầu tiên chúng tôi sử dụng thời gian dùng để lắng đọng các hạt $\mathrm{Ag}$ là 1 phút, tương tự thời gian lắng đọng các hạt $\mathrm{Ag}$ trên các dây nano Si [1]. Kết quả chụp các ảnh SEM cho thấy với các mẫu PSiC ăn mòn với mật độ dòng nhỏ hơn $2,5 \mathrm{~mA} / \mathrm{cm}^{2}$ thì có rất ít các hạt $\mathrm{Ag}$ được tạo thành trên mẫu, thêm nữa các hạt này có kích thước trung bình rất nhỏ (< $10 \mathrm{~nm}$ ). Với các mẫu ăn mòn với mật độ dòng từ $2,5 \mathrm{~mA} / \mathrm{cm}^{2}$ trở lên thì các hạt $\mathrm{Ag}$ được tạo thành trên mẫu là nhiều hơn và kích thước trung bình lớn hơn, mẫu ăn mòn với mật độ dòng $3,5 \mathrm{~mA} / \mathrm{cm}^{2}$

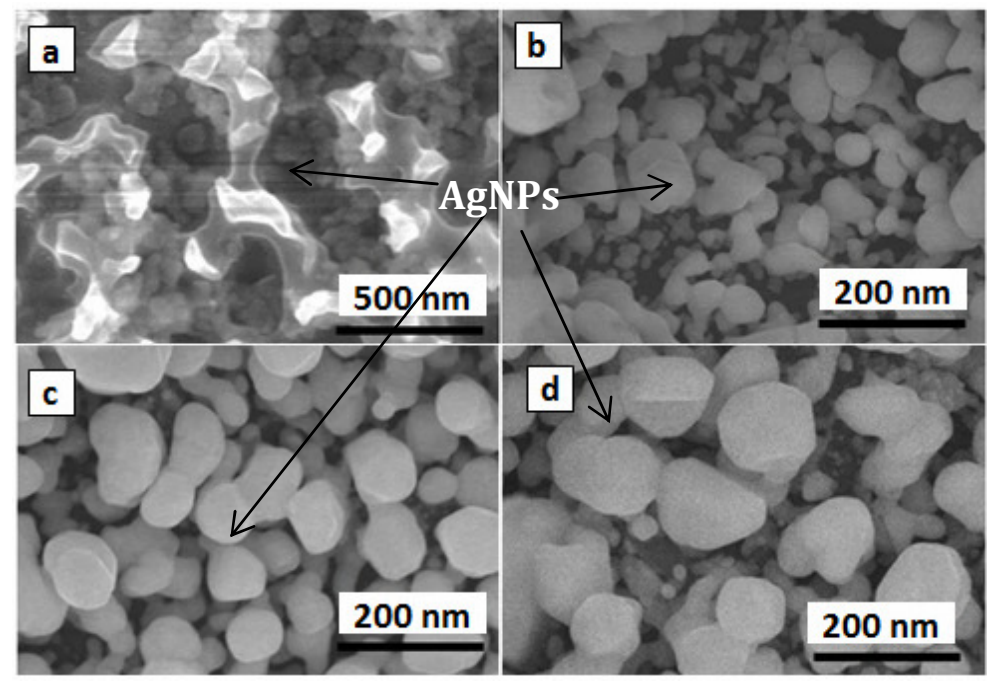

Hình 1. Anh SEM bề mặt các mẫu 3i-aSiC xốp ăn mòn anốt trong dung dịch $0,5 \% \mathrm{HF} / \mathrm{H}_{2} \mathrm{O}$ với mật độ dòng $3,5 \mathrm{~mA} / \mathrm{cm}^{2}$ sau khi đuợc lắng đọng các hạt $\mathrm{Ag}$ trong dung dịch $\mathrm{HF}_{\mathrm{AgNO}}=$ 4,6(M)/25(mM) trong (a) 1, (b) 3, (c) 5 và (d) 7 phút. cho các hạt bạc to nhất và nhiều nhất, nhưng lúc này các hạt $\mathrm{Ag}$ chủ yếu nằm ở đáy lỗ xốp (như trên Hình 1a). 
Sau đó chúng tôi sử dụng mẫu $\mathrm{PSiC}$ ăn mòn với mật độ dòng $3,5 \mathrm{~mA} / \mathrm{cm}^{2}$ để tăng thời gian lắng đọng các hạt $\mathrm{Ag}$. Kết quả cho thấy khi tăng thời gian lắng đọng thì kích thước các hạt $\mathrm{Ag}$ tăng lên đồng thời phủ kín toàn bộ mặt mẫu (như trên Hình $1 b-\mathrm{d}$ ). Mẫu lắng đọng trong thời gian 5 phút (Hình 1c) cho các hạt $\mathrm{Ag}$ có kích thước đồng đều nhất với đường kính trung bình của hạt $\mathrm{Ag}$ cỡ $90 \mathrm{~nm}$. Khi thời gian lắng đọng tăng lên 7 phút (Hình $1 \mathrm{~d}$ ) thì đường kính trung bình của các hạt $\mathrm{Ag}$ lên tới $150 \mathrm{~nm}$ đồng thời mật độ các hạt thưa hơn.
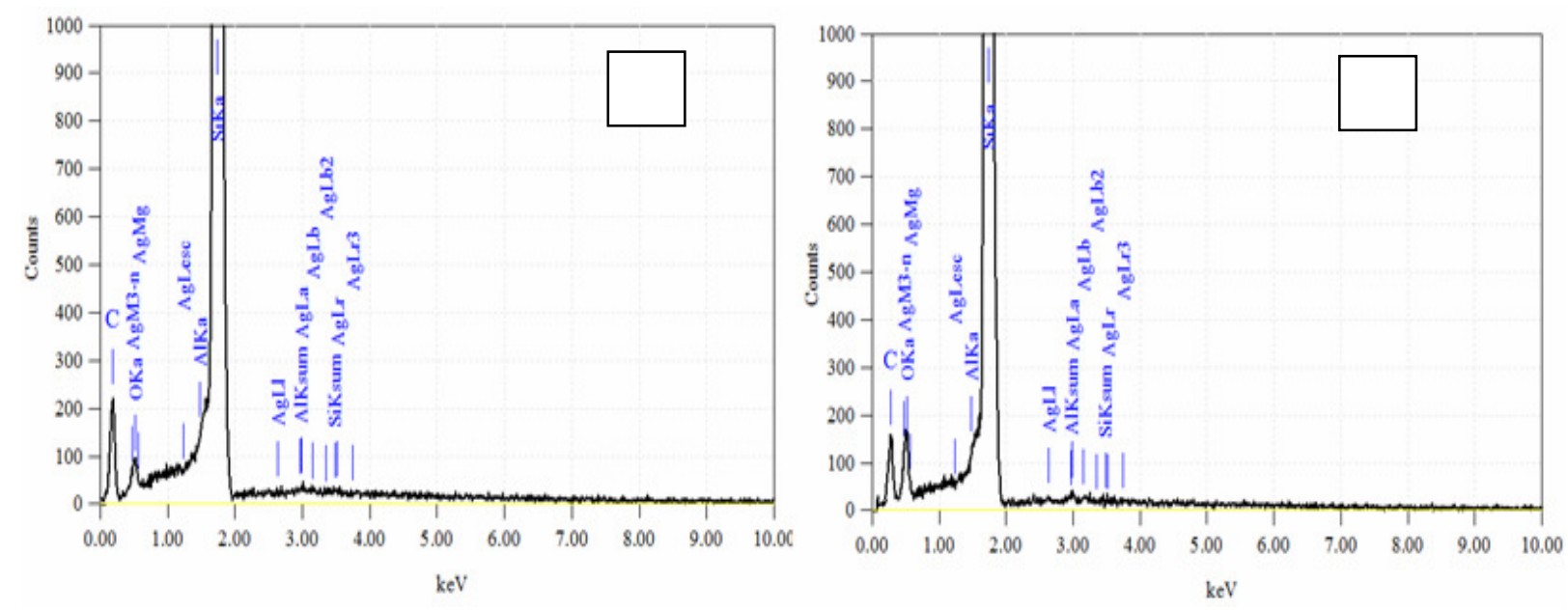

Hình 2. Phổ EDX của đế SERS chế tạo tù mẫu 3i-aSiC xốp ăn mòn anốt bằng dung dịch 0,5\% $\mathrm{HF} / \mathrm{H}_{2} \mathrm{O}$ với mật độ dòng $3,5 \mathrm{~mA} / \mathrm{cm}^{2}$ trong thời gian 50 phút, sau đó được lắng đọng các hạt nano $\mathrm{Ag}$ trong dung dịch $\mathrm{HF}_{\mathrm{AgNO}}=4,6(\mathrm{M}) / 25(\mathrm{mM})$ với thời gian 1 (a) và 5 (b) phút.

Để khẳng định chắc chắn sự hình thành của các hạt nano Ag trên các đế SERS thì ngoài việc chụp ảnh SEM chúng tôi cũng đã tiến hành phân tích hàm lượng các nguyên tố trên các đế SERS bằng phương pháp huỳnh quang tia $X$ và EDX. Các kết quả đều cho thấy rõ sự có mặt của $\mathrm{Ag}$ trên các đế SERS. Trên Hình 2 là phổ EDX của đế SERS chế tạo từ mẫu 3i-aSiC xốp ăn mòn anốt bằng dung dịch $0,5 \% \mathrm{HF} / \mathrm{H}_{2} \mathrm{O}$ với mật độ dòng $3,5 \mathrm{~mA} / \mathrm{cm}^{2}$ trong thời gian 50 phút, sau đó được lắng đọng các hạt nano $\mathrm{Ag}$ trong dung dịch $\mathrm{HF} / \mathrm{AgNO}_{3}=4,6(\mathrm{M}) / 25(\mathrm{mM})$ với thời gian khác nhau. Các phổ này cho ta thấy rõ sự tạo thành của $\mathrm{Ag}$ ở trên các đế SERS.

Sau khi lắng đọng các hạt $\mathrm{Ag}$ chúng tôi tiến hành khảo sát sự tăng cường tín hiệu SERS của đế AgNPs@PSiC. Chất được dùng để thử là $\mathrm{MG}$, công thức hóa học của nó là $\mathrm{C}_{23} \mathrm{H}_{25} \mathrm{ClN}_{2}$. Đây là chất thường được sử dụng như một loại thuốc nhuộm cho vật liệu như lụa, da và giấy. Ngoài ra, MG cũng được sử dụng rộng rãi như một loại thuốc diệt nấm trong ngành công nghiệp cá trên toàn thế giới. Tuy nhiên, việc sử dụng loại thuốc nhuộm này đã gây ra nhiều mối quan ngại, do tác dụng độc hại của nó. MG gần đây đã được thông báo là gây ra ung thư, đột biến nhiễm sắc thể và nhiễm độc đường hô hấp đối với động vật tiếp xúc với nó [18]. Trong thời gian gần đây tại Việt Nam MG đã được sử dụng một cách bất hợp pháp để nhuộm màu thực phẩm, làm cho thực phẩm trở thành có màu xanh lá cây ví dụ như nhuộm màu cốm, bánh cốm. Điều này sẽ ảnh hưởng nghiêm trọng sức khỏe của những người sử dụng thực phẩm. Do đó việc phát hiện sự tồn dư của $\mathrm{MG}$ trong thực phẩm là rất quan trọng.

Trong thí nghiệm của mình, đầu tiên chúng tôi sử dụng dung dịch $\mathrm{MG}$ có nồng độ $10^{-5} \mathrm{M}$ với lượng dung dịch nhỏ giọt lên $1 \mathrm{~cm}^{2}$ mẫu là $50 \mu$ l. Bước sóng laser dùng để kích thích mẫu là 532 
nm. Trên hình 3 là phổ Raman của MG được nhỏ giọt trên các mẫu aSiC xốp ăn mòn anốt trong dung dịch nước của $0,5 \% \mathrm{HF} / \mathrm{H}_{2} \mathrm{O}$ với mật độ dòng $3,5 \mathrm{~mA} / \mathrm{cm}^{2}$ sau khi lắng đọng các hạt $\mathrm{Ag}$ trong dung dịch $\mathrm{HF} / \mathrm{AgNO}_{3}=4,6(\mathrm{M}) / 25(\mathrm{mM})$ trong (a)1, (b) 3 và (c) 5 phút. Từ hình 3 ta có thể thấy rõ sự tăng lên của cường độ Raman khi thời gian lắng đọng hạt $\mathrm{Ag}$ tăng từ 1-5 phút, với mẫu 7 phút thì cường độ Raman lại giảm đi so với mẫu 5 phút nên chúng tôi không trình bày trên hình. Trong các phổ này chúng ta đều thấy sự xuất hiện của các đỉnh phổ đặc trưng của $\mathrm{MG}$, cụ thể là: tín hiệu quan sát tại $914 \mathrm{~cm}^{-1}$ được cho là do các dao động vòng khung xuyên tâm; các tín hiệu tại 1171 và 1294 $\mathrm{cm}^{-1}$ đến từ dao động uốn trong mặt phẳng $\mathrm{C}-\mathrm{H}$ của vòng thơm; tín hiệu tại $1366 \mathrm{~cm}^{-1}$ được đóng góp từ sự căng $\mathrm{N}-\mathrm{C}$; tín hiệu tại $1394 \mathrm{~cm}^{-1}$ đến từ dịch chuyển phẳng $\mathrm{C}-\mathrm{C}$ và $\mathrm{C}-\mathrm{H}$ (của vòng thơm) và các tín hiệu ở $1617 \mathrm{~cm}^{-1}$ được quy cho N-C (liên kết $\varphi$ ) và sự căng C-C [1].

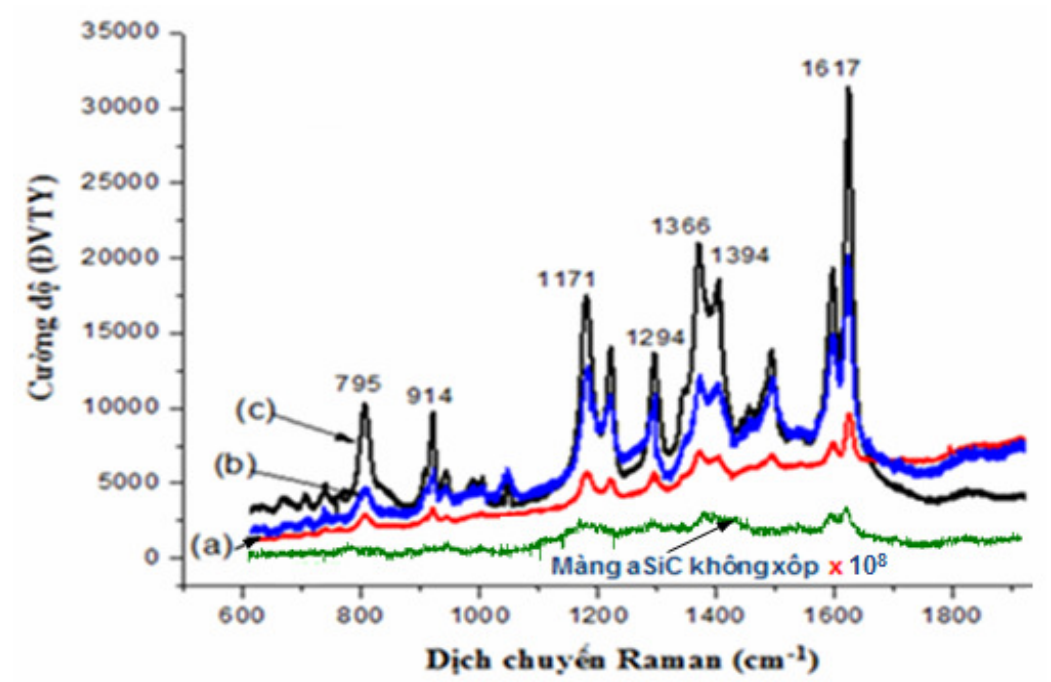

Hình 3. Phổ Raman được kích thích bằng bước sóng $532 \mathrm{~nm}$ của mẫu nhỏ giọt $M G$ với nồng độ $10^{-5} \mathrm{M}$ trên đế aSiC xốp ăn mòn trong dung dịch $0,5 \% \mathrm{HF} / \mathrm{H}_{2} \mathrm{O}$ với mật độ dòng $3,5 \mathrm{~mA} / \mathrm{cm}^{2}$ được lắng đọng các hạt Ag trong dung dịch $\mathrm{HF} / \mathrm{AgNO}_{3}=$ $4,6(M) / 25(m M)$ vói thòi gian (a) 1 , (b) 3 và (c) 5 phút.

Để đánh giá hiệu quả của đế SERS mà chúng tôi chế tạo được, chúng tôi tính chỉ số tăng cường Raman (Raman Enhancement Factor-REF) theo công thức [19]:

$$
\operatorname{REF}=\frac{I_{\text {SERS }} \cdot N_{\text {RS }}}{I_{\text {RS }} \cdot N_{\text {SERS }}}
$$

Ở đây $\mathrm{I}_{\mathrm{SERS}}$ là cường độ Raman của một đỉnh tín hiệu nào đó của phân tử chất phân tích (thường chọn đỉnh mạnh nhất) khi có đế $\mathrm{SERS}, \mathrm{I}_{\mathrm{RS}}$ là cường độ Raman của một đỉnh tín hiệu của phân tử chất phân tích khi không có đế tương ứng với đỉnh đã chọn khi có đế SERS, $\mathrm{N}_{\mathrm{SERS}}$ và $\mathrm{N}_{\mathrm{RS}}$ là số nguyên tử của chất phân tích trên bề mặt đế SERS và đế không có $\mathrm{SERS}$ trên cùng một đơn vị diện tích. Trong trường hợp này chúng tôi chọn đỉnh ở $1617 \mathrm{~cm}^{-1}$ để tính REF. Kết quả đế SERS có cường độ Raman mạnh nhất của chúng tôi có chỉ số tăng cường REF có giá trị là 1,02.109 . Trong công nghệ SERS thì đây được coi là chỉ số khá cao [13, 14].

Sau khi tìm ra đế SERS có hệ số tăng cường Raman mạnh nhất, chúng tôi sử dụng đế SERS này để khảo sát ngưỡng phát hiện MG. Kết quả cho thấy nồng độ MG nhỏ nhất mà đế SERS chế tạo từ lớp aSiC xốp có thể phát hiện được là $10^{-9} \mathrm{M}$. Kết quả này là tốt hơn so với kết quả mà chúng tôi đã từng công bố trước đây khi nghiên cứu chế tạo các đế SERS trên các hệ dây nano Si thẳng đứng sắp xếp thẳng hàng [1] nhưng kém hơn so kết quả mà chúng tôi đã từng công bố trước đây khi nghiên cứu chế tạo các đế SERS trên các hệ dây nano Si nghiêng sắp xếp thẳng hàng [17]. 


\section{Kết luận}

Bằng việc sử dụng phương pháp lắng đọng hóa học, chúng tôi đã chế tạo được hệ các đế AgNPs@PSiC. Các kết quả thu được cho thấy rằng hình thái cấu trúc của các AgNPs trên PSiC phụ thuộc vào thời gian lắng đọng bạc và hình thái của lớp $\mathrm{PSiC}$. Mẫu được lắng đọng bạc trong thời gian 5 phút trên đế $\mathrm{PSiC}$ xốp ăn mòn với mật độ dòng $3,5 \mathrm{~mA} / \mathrm{cm}^{2}$ cho hình thái cấu trúc hệ AgNPs@PSiC tối ưu nhất để làm các đế SERS với kích thước các hạt là 80100 nm. Cụ thể là, nếu sử dụng MG là chất phân tích thì đế AgNPs@PSiC tối ưu nhất sẽ cho hệ số tăng cường Ramasoosleen đến $10^{9}$ lần. Các đế có kích thước của AgNPs lớn hơn 100 nm thì hiệu suất tăng cường Raman sẽ càng giảm đi. Các đế AgNPs@ $\mathrm{PSiC}$ có thể sử dụng để làm các đế SERS để phát hiện các phân tử MG với giới hạn phát hiện có thể thấp đến $10^{-9} \mathrm{M}$.

\section{Lời cảm ơn}

Các tác giả xin cảm ơn cử nhân Lê Văn Long - Viện Khoa học Vật liệu đã giúp thực hiện các phép đo ghi phổ Raman. Các kết quả nghiên cứu này được tài trợ bởi Quỹ Phát triển Khoa học và Công nghệ Quốc gia Việt Nam (NAFOSTED) thông qua đề tài số 103.022013.42 .

\section{TÀI LIỆU THAM KHẢO}

1. T.Q.N. Luong, T.A. Cao and T.C. Dao (2013), "Low-concentration organic molecules detection via surface-enhanced Raman spectroscopy effect using Ag nanoparticles-coated silicon nanowire arrays" (Phát hiện các phân tử hữu cơ nồng độ thấp thông qua hiệu ứng phổ Raman tăng cường bề mặt sử dụng các hạt nano $\mathrm{Ag}$ bao phủ hệ dây nano silic), Adv. Nat. Sci.: Nanosci. Nanotechnol., 4 (1), 015018 (5pp).

2. H. Xu, J. Aizpurua, M. Kall, and P. Apell (2000), "Electromagnetic contributions to single-molecule sensitivity in surface-enhanced raman scattering” (Đóng góp của điện từ trường to độ nhạy đơn phân tử trong tán xạ Raman tăng cường bề mặt), Phys. Rev. E, 62 (3), 4318 4324.

3. C. Q. Yi, C.W. Li, H.Y. Fu, M.L. Zhang, S.J. Qi, N.B. Wong, S.T. Lee, and M.S. Yang (2010), "Patterned growth of vertically aligned silicon nanowire arrays for label-free DNA detection using surface-enhanced Raman spectroscopy" (Mọc có tạo khuôn các hệ dây nano silic thẳng đứng xếp thẳng hàng cho nhận biết AND đánh dấu tự do sử dụng phổ Raman tăng cường bề mặt), Anal. Bioanal. Chem., 397 (7), 3143 - 3150.

4. Z. Zhou, X.X. Han, G.G. Huang, and Y. Ozaki (2012), "Label-free detection of binary mixtures of proteins using surface-enhanced Raman scattering" (Phát hiện đánh dấu tự do của hốn hợp các protein sử dụng tán xạ Raman tăng cường bề mặt), J. Raman Spectrosc., 43 (6), 706-711.

5. S. Huang, J. Hu, P. Guo, M. Liu and R. Wu (2015), "Rapid detection of chlorpyriphos residue in rice by surface-enhanced Raman scattering” (Phát hiện nhanh dư lượng chlorpyriphos trong gạo bằng tán xạ Raman tăng cường bề mặt), Anal. Methods, 7 (10), 4334-4339.

6. W. Wijaya, S. Pang, T.P. Labuza, L. He (2014), "Rapid detection of acetamiprid in foods using surface-enhanced Raman spectroscopy (SERS)" (Phát hiện nhanh acetamiprid trong thực phẩm sử dụng phổ Raman tăng cường bề mặt (SERS)), J. Food Sci., 79 (4), T743- T747. 
7. A. Sengupta, M. Mujacic, E.J. Davis (2006), "Detection of bacteria by surface-enhanced Raman spectroscopy” (Phát hiện vi khuẩn bằng phổ Raman tăng cường bề mặt), Anal Bioanal Chem., 386 (5), 379-86.

8. S. Pahlow, S. Meisel, D. Cialla-May, K. Weber, P. Roscha, J. Popp (2015), “Isolation and identification of bacteria by means of Raman spectroscopy" (Phân lập và xác định vi khuẩn bằng phương pháp quang phổ Raman), Advanced Drug Delivery Reviews, 89 (4), 105-120.

9. W.E. Smith, G. Dent (2005), "Modern Raman Spectroscopy - a Practical Approach" (Phổ Raman hiện đại - một phương pháp tiếp cận thực tế), New York, Wiley.

10. Fleischmann M, Hendra P J and McQuillan A J (1974), "Raman spectra of pyridine adsorbed at a silver electrode" (Phổ Raman của pyridine hấp thụ ở điện cực bạc), Chem. Phys. Lett., 26 (2), 163-166.

11. P. C. Lee and D. Meisel (1982), “Adsorption and surface-enhanced Raman of dyes on silver and gold sols" (Sự hấp thụ và Raman tăng cường bề mặt của chất màu trên dung dịch bạc và vàng), Phys. Chem., 86 (17), 3391-3395.

12. J. Zhang, X. Li, X. Sun, and Y. Li (2005), "Surface Enhanced Raman Scattering Effects of Silver Colloids with Different Shapes" (Hiệu ứng tán xạ Raman tăng cường bề mặt của huyền phù bạc với các hình dạng khác nhau), J. Phys. Chem. B, 109 (25), 12544-12548.

13. C. Zhang, B.Y. Man, S.Z. Jiang, C. Yang, M. Liu, C.S. Chen, S.C. Xu, H.W. Qiu, Z. Li (2015), "SERS detection of low-concentration adenosine by silver nanoparticles on silicon nanoporous pyramid arrays structure" (SERS sự phát hiện nồng độ thấp của adenosine bằng các hạt nano bạc trên các mảng cấu trúc hình chóp silic nano xốp), Appl. Surf. Sci., 347 (10), 668672 .

14. C. Leordean, B. Marta, A.-M. Gabudean, M. Focsan, I. Botiz, S. Astilean (2015), "Fabrication of highly active and cost effective SERS plasmonic substrates by electrophoretic deposition of gold nanoparticleson a DVD template" (Chế tạo các đế SERS plasmonic hiệu suất cao và giá thành hợp lý bằng lắng đọng điện li các hạt nano vàng trên đế DVD ), Appl. Surf. Sci., 349 (14), 190-195.

15. L.T. Quynh-Ngan, D.T. Cao, C. T. Anh; L.V. Vu (2015), "Improvement of Raman enhancement factor due to the use of silver nanoparticles coated obliquely aligned silicon nanowire arrays in SERS measurements" (Cải thiện hệ số tăng cường Raman do việc sử dụng các hạt nano bạc bao phủ lên hệ dây nano silic nghiêng sắp xếp thẳng hàng trong việc đo đạc SERS), Int. J. of Nanotechnology, 12 ( 5/6/7), 358 - 366.

16. A.M. Michaels, M. Nirmal, and L.E. Brus (1999), "Surface Enhanced Raman Spectroscopy of Individual Rhodamine 6G Molecules on Large Ag Nanocrystals" (Phổ Raman tăng cường bề mặt của các phân tử Rhodamine $6 \mathrm{G}$ riêng lẻ trên nano tinh thể $\mathrm{Ag}$ lớn), J. Am. Chem. Soc., 121(43), 9932-9939.

17. A.T. Cao, Q.-N.T. Luong and C.T. Dao (2014), "Influence of the anodic etching current density on the morphology of the porous SiC layer" (Ảnh hưởng của mật độ dòng anốt lên hình thái của lớp SiC xốp), AIP Advances, 4 (3), 037105 (7pp). 
18. E. Sudova, J. Machova, Z. Svobodova, and T. Vesely (2007), "Negative effects of malachite green and possibilities of its replacement in the treatment of fish eggs and fish: a review" (Tác động tiêu cực của malachite green và khả năng thay thế của nó trong xử lý trứng cá và cá: một tổng quan), Veterinarni Medicina, 52 (12), 527-539.

19. Z.Q.Tian, J.S.Gao, X.Q.Li, B. Ren, Q.J.Huang, W.B.Cai , F.M. Liu and B.W. Mao (1998), "Can surface Raman spectroscopy be a general technique for surface science and electrochemistry?" (Phổ Raman bề mặt có thể là một kỹ thuật phổ biến của khoa học bề mặt và điện hóa?), J. Raman Spectrosc., 29 (8), 703-711.

20. T. C. Dao, T. Q. N. Luong, T.A. Cao, N. H. Nguyen, N. M. Kieu, T. T. Luong and V.V. Le (2015), "Trace detection of herbicides by SERS technique, using SERS-active substrates fabricated from different silver nanostructures deposited on silicon" (Phát hiện lượng vết thuốc diệt cỏ bằng kỹ thuật SERS, sử dụng đế SERS chế tạo từ các cấu trúc nano bạc lắng đọng trên silic), Adv. Nat. Sci.: Nanotechnol. 6 (3), 035012(6pp). 